\title{
EN TORNO A LA RECEPCIÓN DEL NATURALISMO EN ESPAÑA \\ (JOSÉ ORTEGA MUNILLA, LEOPOLDO ALAS, TOMÁS TUERO, LUIS ALFONSO Y \\ LAS RESEÑAS DE LA DESHEREDADA DE GALDÓS)
}

En 1881, el mismo año en que se publica en dos partes diferentes La desheredada de Galdós, aparecen también las reseñas que Clarín escribe de cada una de dichas partes de la novela galdosiana ${ }^{1}$. Son éstas, con toda probabilidad, las más reputadas de cuantas el asturiano escribió sobre la producción novelesca de Galdós. Su importancia objetiva fue rápidamente sentida por los críticos hasta tal punto que un lúcido observador extranjero, el uruguayo José Enrique Rodó, llegó a afirmar que, dentro de la crítica española, y como iniciación de nuevos rumbos, las reseñas antedichas del asturiano representaban lo que el libro de Galdós representó dentro de la novela española ${ }^{2}$. Esta importancia, tan atinadamente subrayada por Rodó, se debe en buena medida a que aquéllas importan, no sólo porque contengan una descripción inicial de la nueva novela, sino porque, trascendiendo la descripción propiamente dicha, tratan de fundar, en la polémica con hipotéticos lectores conservadores, los principios mismos de la novela que la "nueva doctrina" trataba de introducir en España.

Un ejemplo del interés polemizante de Clarín se encuentra en la reseña a la segunda parte de La desheredada, la cual comienza con un apóstrofe de sobra conocido de los estudiosos del xix:

Escandalícense, porque es bien que se escandalicen ahora los críticos meticulosos, partidarios del limitez vous, de que habla Víctor Hugo. Ésta es ocasión de probar este exquisito gusto traducido del fran-

1 Cito por la edición recogida en el libro de Leopoldo Alas, Galdós, Renacimiento, Madrid, 1912. Las citas procedentes de esta edición se señalarán con el número de página entre paréntesis.

2 J. E. RoDó, El que vendrá, cit. por Serglo Besser, Leopoldo Alas, crítico literario, Gredos, Madrid, 1968, pp. 89-90. 
cés, y que consiste en no ver más belleza que la que puede sacarse de lo lindo, de lo atusado y aromático; ¡Galdós se ha echado en la corriente; ha publicado su programa de literatura incendiaria, su programa de naturalista; ha escrito en quinientas siete páginas la historia de una prostituta! Excomulguémosle, porque es bien que le excomulguemos. Digo más, y digo con Santo Tomás: Juste occidi. ¡Que muera! (p. 104).

En este párrafo Clarín da cuenta del cambio que ha experimentado la novela galdosiana. Pero, yendo más allá de la mera descripción, pasa inmediatamente a subrayar precisamente de qué modo Galdós se hace eco de las nuevas corrientes naturalistas que, procedentes de Francia, habían comenzado a hacer su aparición poco antes en las letras españolas ${ }^{3}$.

Puesto que el interés de Clarín no es exclusivamente descriptivo, el asturiano busca polemizar con futuros lectores que pudieran oponerse a la tendencia que él describe como novedosa en la producción literaria de Galdós. Se busca, así, llegar al enfrentamiento con el "lector idealista", que el crítico menciona en la reseña a la segunda parte de la novela cuando dice: "El lector idealista, a quien supongo pasmado de indignación ante el lenguaje de Gaitica e Isidora en su noviciado de prostitución, es muy posible que tache también al novelista por su poca invención y por falta de arte para componer" (p. 109). De este modo, mediante el enfrentamiento antedicho, Clarín colabora a desarrollar ese mismo programa "de literatura incendiaria" que él describe. Porque es a este lector idealista, y a la posible apatía del mismo ante lo nuevo, por muy escandaloso que lo nuevo pueda llegar a ser, a quien hay que achacar en última instancia el "silencio" que, en opinión de Clarín, se cierne sobre la nueva novela galdosiana. De dicho silencio - que, dicho sea entre paréntesis, no existió, como habré de explicar más adelante- se ocupa el asturiano acto seguido, en el párrafo que sigue al apóstrofe inicial, diciendo:

Y si el silencio fuese la muerte para el ingenio, para la fama del que ha de vivir en sus obras mucho más de lo que puede durar esta generación hipócrita y sin gusto, bien muerto estaría Galdós, o por lo menos La Desheredada. ¿Saben ustedes algo de lo que ha dicho la crítica de La Desheredada? ¿Han escrito los periódicos populares, con

${ }^{3}$ Las primeras noticias llegan a través de los trabajos de Felipe Benicio Navarro, aparecidos en la Revista de España entre 1877 y 1879; véase W. T. Pattison, El naturalismo español, Gredos, Madrid, 1969, pp. 14-17. 
motivo de este libro, artículos de sensación, de los que tienen un titulejo o rótulo especial para cada párrafo? Nada; el silencio. Yo he leído entre tanto cincuenta bombos de los mapas geográfico-estadístico-pedagógicos de Vallín y Bustillo; sesenta reclamos de Figuras y figurones; mil encomios de la obra que tiene emprendida el Sr. Novo..., pero nadie ha dicho a La Desheredada, por ahí te pudras (p. 105).

Clarín, en definitiva, busca agitar las conciencias de sus contemporáneos al mismo tiempo que llama la atención de éstos sobre un hecho que él considera de extraordinaria importancia en aquel momento. Pues Galdós, que había sido por él descrito pocos meses antes como el mejor novelista español del momento, acababa de pasarse con armas y bagajes a la nueva corriente naturalista. En efecto, en el ensayo "El libre examen y nuestra literatura presente" ya había escrito Clarín que, de los novelistas españoles del momento, “el más atrevido, el más avanzado, por usar una palabra muy expresiva [...] y también el mejor, con mucho, de todos ellos es Benito Pérez Galdós"'4. A señalar el tránsito susodicho, por último, había dedicado Clarín la reseña de la primera parte de La desheredada, concluyendo con las siguientes palabras:

Aquí sólo me he propuesto notar la tendencia naturalista, en el buen sentido de la palabra, de la última obra de Galdós; tendencia que yo aplaudo, porque estimo que, bien interpretada, la teoría del naturalismo lleva la mejor parte en la lucha de las escuelas, y sobre todo en la práctica del arte. Es claro que en Galdós ese naturalismo no puede ser servil imitación, sino original manera; y, en efecto, como veremos el día que se trate de esta novela más despacio, lleva en ella el naturalismo un sello singular, el de la personalidad de su autor, quizá el novelista de más equilibradas facultades, menos amanerado, más parsimónico y prudente entre cuantos grandes novelistas hoy trabajan en la transformación lenta, pero infalible, de la literatura contemporánea (p. 104).

Guiado, pues, por una intención polémica, en la reseña a la segunda parte de La desheredada Clarín presta especial atención al efecto que sus palabras han de producir en futuros lectores.

Paradójicamente, sin embargo, es precisamente el carácter po-

4 "El libre examen y nuestra literatura presente", recogido en Solos de Clarin, Alianza, Madrid, 1971, p. 72; subraya Clarín. 
lémico de las dos reseñas de Clarín lo que ha oscurecido su importancia objetiva, y lo que, de hecho, ha llevado a algunos críticos contemporáneos a desconsiderar dichas reseñas como descripciones atinadas de la novela galdosiana. Robert Ricard rechazaba, por ejemplo, en 1961, la habitual separación en dos períodos de la producción galdosiana, propuesta por Casalduero entre otros ${ }^{5}$, porque - decía el mencionado crítico francés- no está claro que los contemporáneos del novelista notaran un cambio fundamental en la producción galdosiana en el momento de publicarse ${ }^{6}$. Años después, en 1971, Richard Cardwell tomaba esta hipótesis de Ricard como punto de partida para desarrollar, en un artículo memorable en muchos aspectos, la base conceptual de una hipótesis más tarde desarrollada en su mayor parte por Brian Dendle.

- En una formulación reciente este último expone sus dudas sobre el valor crítico de las reseñas de Clarín, diciendo:

¿Por qué se ha empeñado tanto la crítica en clasificar La desheredada como "novela naturalista"? El origen de este eıror debe buscarse en la exagerada importancia dada a las dos reseñas escritas por Clarín al publicarse la novela y en cierta ignorancia crítica del contexto en que escribía Clarín. Clarín era un hombre joven, de unos veintiocho años, sin conocimiento especial del propósito de Galdós (en otra parte he demostrado su interpretación errónea de dos novelas anteriores de Galdós, Gloria y Marianela); estaba reseñando separadamente las dos partes de La desheredada para la prensa popular. Sus reseñas son poco más que una publicidad para la última novela galdosiana. El entusiasmo clariniano por Zola, y su fácil identificación del naturalismo con el espíritu moderno en la literatura, le habrían llevado a ensalzar La desheredada como obra de la nueva escuela. En la reseña de la segunda parte de la novela, es evidente que Clarín considera La desheredada y el "naturalismo" armas en su campaña contra la novela idealista?.

Dendle rechaza aquí el valor descriptivo de la reseña clariniana en razón del marcado carácter polémico de ésta, a lo que se 67 ss.

${ }^{5}$ Joaquín Casalduero, Vida y obra de Galdós, Gredos, Madrid, 1961, pp.

${ }^{6}$ R. Ricard, Galdós et ses romans, P.U.F., Paris, 1961, cit. por R. A. CardWELl, "Galdós's early novels and the segunda manera: A case for a total view", Renaissance and Modern Studies, 15 (1971), 44-62.

7 BRian J. Dendle, "Galdós, Zola y el naturalismo de La desheredada", en Y. Lissorges (ed.), Realismo y naturalismo en España en la segunda mitad del siglo xix, Anthropos, Barcelona, 1988, p. 455. 
une, en palabras del crítico, la juventud de su autor, que contaba veintiocho años en 1881. Pero de más importancia en este rechazo resulta la apelación que Dendle hace al contexto en que escribe Clarín. Y esta apelación importa porque, a pesar de lo sugerido por Dendle, una ojeada cuidadosa a dicho contexto crítico viene precisamente a ratificar la opinión de Clarín. Pues los otros críticos que se ocuparon de la novela galdosiana en el momento de su publicación - Tomás Tuero, Luis Alfonso, José Ortega Munilla y Emilia Pardo Bazán - se dieron inmediatamente cuenta de que en efecto se había producido un cambio en la forma de novelar de Galdós. Y lo que es sin duda más importante, todos ellos fueron pronto conscientes de que dicho cambio habría de ser de fundamental importancia para la transformación del género novelesco español.

De hecho, propiamente hablando, en lo único en que Clarín no acierta es al considerar que la novela galdosiana había sido recibida en "silencio". Pues una reacción análoga a la suya, e igualmente entusiasta, tiene el crítico Tomás Tuero ${ }^{8}$, autor de una importante reseña de La desheredada aparecida en La Iberia el viernes 30 de septiembre de 1881 , esto es, casi un mes antes de que se publicara la reseña de Clarín a la segunda parte de la novela. En ella, Tuero escribe:

El Sr. Pérez Galdós [... ] dirige hoy [su talento] por nuevos rumbos. Lo hemos dicho al principio: el naturalismo se impone decididamente, y he aquí al Sr. Galdós, el ilustre autor de tantas novelas históricas y novelas de tesis, todas ellas muy justamente celebradas, abandonando las realidades del pasado y renunciando a resolver pro-

${ }^{8}$ Tomás Tuero es, según Clemessy, el seudónimo literario usado por el abogado Manuel Fernández Rodríguez Avello; véase, además, W. T. PAtTISon, $a p$. cit., pp. 20-21, n. 1. Tuero fue, al parecer, el primer traductor de Nana, de Zola, al castellano (PATtison, op. cit., p. 52), y es él quien, ya para 1887, señala que el naturalismo ha muerto al decaer la polémica que lo mantenía vivo en la prensa diaria (pp. 145-146). Hacia 1885, Tuero criticó las novelas de Eduardo López Bago, a quien calificó de autor pornográfico y de quien dijo que no era autor naturalista. LÓPEZ BAGo le responde, en el apéndice a El confesionario (satiriasis), Administración, Madrid, [¿1885?], burlándose de sus escritos, diciendo: "Siga el Sr. Tuero haciendo las clasificaciones que guste; y cuando escriba algo que no sea literatura al por menor, un librejo, "aunque sea tamaño como un grano de trigo", que, como dijo el mercader a Don Quijote, "por el hilo se sacará el ovillo", y yo juro clasificar con más fortuna el género a que pertenece; y aun «si es tuerta la obra, con todo eso, por complacer a vuesa merced, diremos en su favor todo lo que quisiere»" (p. 258). 
blemas para estudiar la vida que le rodea y arrancarle su continuo y palpitante drama ${ }^{9}$.

A esto añade el crítico poco después que el naturalismo, "recibiendo del Sr. Galdós su primer impulso, habrá de ser forzosamente fecundo en resultados", para finalmente concluir que el señor Galdós “'ha hecho una magnífica novela y determinado una evolución que, por él y por los que le sigan, ha de ser de gran trascendencia en nuestra literatura'.

Una opinión, una vez más análoga a las anteriores por lo que se refiere a notar el cambio de orientación en la producción galdosiana, pero expuesta en este caso desde una perspectiva ideológica opuesta ( $y$, por tanto, hay que suponer que sin gana alguna de promocionar el naturalismo), tiene el crítico valenciano Luis Alfonso, quien, tras dejar sentado que él ha sido y continúa siendo escritor "idealista", se detiene a describir el naturalismo de La desheredada apuntando que Galdós "se aprovecha de Zola", para inmediatamente añadir:

«Se aprovecha» he dicho, porque, a mi entender, esta es la frase que mejor traduce mi pensamiento. - Pérez Galdós, como todas las inteligencias superiores, es personal y suyo en sus escritos; pero como todas esas inteligencias igualmente, il prend son bien où il le trouve, como hacía Molière. - Significa, pues, lo dicho que P[érez] Galdós ha leído y estudiado a Zola - el cual, sea dicho de paso, yo, que he sido y soy idealista, tengo en mucho, en tanto como al mejor-, y de esas lecturas y esos estudios ha resultado que el novelista español ha tomado cuanto hay de bueno, o, si se quiere, cuanto hay de aplicable, de oportuno y de productivo en el novelista francés (cf: Apéndice).

Más aún, y en contra de lo que parecen sugerir las palabras de Dendle citadas con anterioridad, la transformación que la novela galdosiana de 1881 supone fue apreciada también (aparte de Clarín) por los novelistas jóvenes más representativos del momento. En 1882, momento en que es bien conocido el interés de la ilustre gallega por el naturalismo, menciona Pardo Bazán La desheredada, indicando que en esta novela aparece un cambio de importancia fundamental en la narrativa del momento: habiendo admitido Pérez Galdós en la novela el lenguaje de los barrios bajos, señaló "rumbos de los cuales no es permitido apartarse ya" ${ }_{10}$.

${ }^{9} \mathrm{Al}$ final he transcrito la reseña de éste así como la de Alfonso.

10 Pardo BazÁn, "Prólogo" a La Tribuna, Cátedra, Madrid, 1981, p. 59. 
Finalmente, el cambio que la novela galdosiana instituye había sido públicamente anunciado por Ortega Munilla en Los Lunes de El Imparcial: antes de la publicación de la novela, el 27 de septiembre de 1880, el padre de Ortega y Gasset informa a los lectores del "nuevo libro" que prepara Pérez Galdós, e indica que su asunto serán "las inteligencias oscuras". Meses más tarde, mientras se publica en entregas semanales la primera parte de $L a$ desheredada, el mismo autor anticipa ya que esta novela de Galdós iniciará un movimiento en la novela española. Dicha obra galdosiana, declara Ortega Munilla, "tendrá una herencia de gloria".

Tanto críticos como novelistas notaron inmediatamente el cambio iniciado y rápidamente instituido por Galdós con su novela de 1881, cambio que deja sentir su efecto en la nueva escritura $\mathrm{y}$, en concreto, en la crítica. Importa así tener presente que, a diferencia de lo que ocurre con la crítica de la época, que es temática en su práctica totalidad, los tres autores de reseñas antes citados - Alas, Alfonso y Tuero- coinciden al destacar importantes innovaciones formales y estructurales en la novela galdosiana de 1881. Coinciden, pues, todos ellos en señalar la sencillez de la trama en la novela de Galdós, sencillez que permitiría emparentarla formalmente con el concepto expuesto por Zola según el cual es menester eliminar de la novela moderna todo elemento novelesco ${ }^{11}$. Señala así Clarín, sin cejar en su propósito polemizador, que el "lector idealista [...] es muy posible que tache también al novelista por su poca invención y por falta de arte para componer"' (p. 109). Y, con menos voluntad de polemizar, coinciden con el asturiano los otros dos, Tomás Tuero y Luis Alfonso, el primero hablando de la sencillez del argumento, y declarando el segundo, en términos nada ambiguos por lo que se refiere a los horizontes de referencia galdosianos, lo siguiente:

Intriga dramática muy simple, fábula muy ligera, peripecias y sorpresas escasísimas o, en frase más breve y usual, poco argumento y prolija abundancia de pormenores afiligranados con admirable minuciosidad y arte exquisito: he aquí el procedimiento literario actual de P. Galdós y el de Zola y el de Daudet, su Rey colega en el trono de la novela francesa contemporánea (cf. Apéndice).

Para un estudio detallado de la variación de estilo que imprime La desheredada en el género novelesco español, véase mi libro Realismo y ficción: "La desheredada" de Galdós y la novela de su tiempo, P.P.U., Barcelona, 1989, pp. 93-129.

${ }^{11} \mathrm{E}$. ZoLA, Les romanciers naturalistes, oeuvres completes, F. Brenouard, Paris, 1927 , t. 44 , p. 108. 
Clarín y Tuero, además, comparten un interés análogo por la novedad - y calidad - en la representación del pueblo en la novela. En la representación del pueblo encuentran ambos críticos uno de los aspectos distintivos del naturalismo galdosiano; un naturalismo que, como vienen a indicar los ataques al romanticismo al comienzo de las reseñas de Clarín y Tuero, se caracteriza inicialmente por la eliminación de los aspectos fantásticos característicos de las representaciones previas. De ahí que Clarín escriba que:

El pueblo que se pinta en La Desheredada -dice Clarín- no es aquel pueblo inverosímil, de guardarropía, de las novelas cursis, que tanto tiempo hicieron estragos en parte del público: es claro que eso no podía ser; pero tampoco es el pueblo idealizado de las novelas socialistas de Sué; en éstas, y en las de otros autores que siguieron a tan notable escritor, las clases últimas (ya que así se [las] llama) aparecen en fantásticas proporciones (p. 100).

Similar reacción se encuentra en la reseña de Tomás Tuero, quien afirma: "El Sr. Pérez Galdós empieza su tarea por donde debía empezar, el pueblo. [...] [pero] Galdós no aborda al pueblo con esa franqueza ruda característica de la nueva novela'.

Finalmente, tanto Tuero como Clarín alaban la figura central de Isidora Rufete. Pero de suprema importancia me parece la observación hecha por Tuero quien, al encarecer el valor artístico de la protagonista, escribe que "Isidora no debió de vivir en Madrid, no era este su medio natural. Esa mujer no es mujer española", para concluir, por último, que su origen es sin duda francés. Importa esta afirmación porque, consideradas las observaciones clarinianas a la luz de estos juicios de Tuero, somos capaces hoy de advertir en qué medida el personaje de Isidora fue sentido por los lectores del momento como producto del estilo. $\mathrm{O}$, dicho de otro modo, el personaje protagonista de la novela galdosiana fue percibido por los críticos del momento como invención ficticia. No pocos lectores, por tanto, hubieron de notar la separación respecto al fuerte contenido moral presente en la anterior posición krausista, un contenido anticipado por Urbano González Serrano quien, al reseñar Doña Perfecta, escribía: 'Puede la novela, por sus especialísimas condiciones, llegar a constituirse en obra de trascendencia social, política y aun religiosa"'12.

12 “Doña Perfecta. Novela original de P. Galdós", El Imparcial (31 de julio de 1877), portada. 
De lo anterior se desprende que La desheredada viene a marcar un cambio, no sólo en la producción novelesca de Galdós, sino también en el entendimiento de la novela por los lectores del período, sirviendo por ello de punto de referencia para las creaciones ulteriores de Galdós y para el entendimiento de éstas por otros escritores. Como ejemplo de ello desearía citar un texto posterior de Clarín. Tres años después, hablando de Tormento, novela galdosiana de 1884, el asturiano recuerda la innovación estilística que supuso el personaje de la novela de 1881. Escribe Clarín: "Isidora es, en rigor, la primer hembra hecha por Galdós con esmero, observación y gran cuidado [ . . ] la caída lenta, azarosa de Isidora es la obra maestra de Galdós"' (p. 129). Importa tener presente que en ese mismo año de 1884 Clarín está componiendo la caída lenta y azarosa de su propia creación: Ana Ozores, protagonista de La Regenta ${ }^{13}$. Diecisiete años después Galdós hace uso de una cita de Wieland para, al comienzo de su prólogo a la segunda edición de la novela de Clarín, reconocer el valor supremo de la ficción. En tal ocasión escribe Galdós: "los pensamientos de los hombres valen más que sus acciones, y las buenas novelas más que el género humano" 14 .

Reproduzco a continuación los textos de las dos reseñas de $L a$ desheredada que he venido citando, textos debidos a Tuero y Alfonso, así como las notas iniciales, escritas por Ortega Munilla para anunciar el libro venidero de Galdós en 1880, y para acusar recibo de la puesta en venta de la primera parte. A diferencia de lo que ocurre con las reseñas escritas por Alas, los textos incluidos aquí son prácticamente desconocidos por la crítica. Y, sin embargo, su conocimiento parece ser indispensable pues aportan el necesario punto de referencia para entender el contexto en el que Clarín escribe sus reseñas. Al reproducir los textos, me ha parecido indispensable corregir la ortografía de los originales. Quede claro, no obstante, que estas modificaciones son puramente ortográficas y siguen la pauta habitual en las ediciones de textos españoles del siglo pasado. En ningún momento afectan estos cambios al contenido de las reseñas.

${ }^{13}$ En otro lugar, Caballero de novela. Ensayo sobre el donjuanismo en la novela española moderna (1880-1930), Puvill, Barcelona, 1986, pp. 77-90, he estudiado con más detalle la posible deuda de La Regenta clariniana con La desheredada de Galdós.

${ }^{14}$ B. PÉrez Galdós, "Leopoldo Alas (Clarín)", en Obras completas, Aguilar, Madrid, 1975, t. 3, p. 1221. 
Como se verá, el texto de Luis Alfonso consta de dos partes, ocupándose la segunda de El capitán Veneno de Pedro Antonio de Alarcón. Incluyo aquí este texto también porque, como he indicado en otro lugar, la novela alarconiana puede ser leída como una reacción contra la renovación instituida por Galdós, y poco importa si esa distinción era consciente o inconsciente; o, para usar una distinción orteguiana, si dicha reacción se fundaba en ideas conscientes o en creencias tácitas ${ }^{15}$. Luis Alfonso mismo comienza su reseña de la segunda novela estableciendo un contraste implícito entre ambas novelas, indicando con ello que responden a dos escuelas de novelar diferentes, siendo por ello susceptibles de dos reacciones estructuralmente diferentes. Esto último explicaría la diferencia que existe en la actitud empleada por el crítico para acercarse a la una o a la otra, una diferencia que, sin ambages, expresa Alfonso mismo al escribir lo siguiente: "No es menester, para tratar el último libro de P. A. de Alarcón, meterse en dibujos ni apelar a filosofías, como para tratar del último de P. Galdós es menester'. El cambio en la forma de novelar, ya lo indiqué más arriba, motiva un cambio análogo en la forma de entender y criticar las novelas. De modo que, el comentario temático que generaba la novela de tesis y la glosa o apostilla críticas dejan paso a las descripciones estructurales y a las observaciones sobre la forma de la novela. Se avanza, pues, no poco en la apreciación de la novela como ficción.

¿Servirán las reseñas y textos aquí reeditados para resolver el problema suscitado por la "segunda manera" galdosiana? Con toda probabilidad no será así. Pero bastará con que permitan una reformulación de dicha polémica desde una nueva perspectiva en la que se hubieran matizado y refinado los planteamientos. Pues, de lo que no cabe duda a la luz de los textos aquí incluidos es de que, contrariamente a lo mantenido inicialmente por Ricard, los contemporáneos de Galdós notaron desde un principio: 1) que se había operado un cambio en la forma de novelar galdosiana; 2) que dicho cambio se asemejaba al naturalismo francés; 3) que la mutación había de tener efectos fructíferos en el género novelesco español y consiguientemente, como he señalado más arriba, en la crítica. La frase de Ortega Munilla - "La desheredada tendrá una herencia de gloria" - , frase repetida o glosada por todos los otros,

15 Ignacio JaVier LóPEz, "Humor y decoro en El capitán Veneno de Alarcón", $B R A E, 234$ (1985), 213-236, y, del mismo, "Alta comedia, realismo y novela en Alarcón", $A L E, 4$ (1985), 197-215. 
podría servir como emblema para resumir esta ampliación y el subsiguiente cambio de actitud.

IGNACJO JAVIER LÓPEZ

University of Pennsylvania

\section{APÉNDICE}

TEXTO I.

José Ortega Munilla, "Galdós", Los Lunes de El Imparcial (Lunes, 27 de septiembre de 1880), p. 1.

También prepara un nuevo libro Pérez Galdós. Pero no aparecerá este año, sino el año 1881. Constará de dos tomos. Parece que Galdós va a pintar en su obra ese sedimento social producido por la ignorancia y la superstición. Ya ha pintado a las descreídas y a las fanáticas. Ahora va a pintar a las inteligencias oscuras, donde el mal chispea esos cerebros que se iluminan en la taberna con las llamas azules del alcohol y en las cuales fermenta el espíritu de las rebeliones sociales. ¡Gran obra digna de Galdós por cierto! ¿Quién podrá llevarla a cabo si él no lo hace?

TeXto 2.

José Ortega Munilla, "Galdós", Los Lunes de El Imparcial (Lunes, 14 de marzo de 1881), p. 1.

Pérez Galdós ha empezado a publicar en cuadernos semanales La Desheredada, una novela que se anuncia y espera hace tiempo. El principio de este libro es la pintura de un manicomio, la casa de Orates de Leganés. ¡Horrible cuadro, lleno de verdad y grandiosa elocuencia! Galdós inaugura una nueva fase de su talento. Una cruda realidad resalta en estas páginas.

La Desheredada tendrá una herencia de gloria.

TeXTo 3.

TomÁs Tuero, "Publicaciones: La desheredada por B[enito] Pérez Galdós", La Iberia (Viernes, 30 de septiembre de 1881).

No hemos de ocultar, a trueque de aparecer harto sensibles, que aún queda en nosotros un cierto residuo de hostilidad hacia esa doctrina naturalista que, poco a poco, y en virtud de su fuerza incontrastable, se va imponiendo a todos definitivamente.

La imaginación ha sido destituida por la nueva escuela ¡La imaginación, con sus alas de oro! Y no sólo no es ya la imaginación la primera excelencia del novelista, sino que se la considera hoy como un elemento perturbador y contraproducente.

¿Por qué negar que antes que el convencimiento, la durísima conclusión engendró en nosotros esa ternura melancólica que se siente ante una tradición 
herida, ante un ideal que se desvanece, ante una religión que se va? ¡Cómo! ¡La imaginación, que ha creado en la novela tan bellas cosas, tan peregrinas fábulas, tan grandiosos personajes como llenan los libros de Hugo, Sand y Gautier, esa imaginación que de la nada, como Dios, sacó mundos, condenada a muerte por sentencia firme, y lo que es más grave aún, formidable de lógica en sus considerandos! ¡Oh! ¡Piedad! ¡Piedad para la imaginación!

No puedo resignarme, no puede satisfacerme por completo ese novelista impasible, semejante a un esbirro de la naturaleza, espía de la realidad, que toma notas y al escribir delata. Sin contar con que en la expresión -bien que en esto no se halle formulado el dogma- el novelista ha de ser sobrio, severo, sin retórica ni lindezas. Sabido es que Stendhal, el primer naturalista, cuando se disponía a trabajar leía dos capítulos del Código Civil, para encontrar el tono.

No, no es posible que la fantasía del escritor resulte de tal suerte anulada, por más que en su obra ponga exclusivamente a contribución la realidad y la vida. No es la novela ya ciertamente aquel rico imaginar de sucesos, combinados por ingenioso modo, con que hábiles narradores conseguían despertar ese interés -en esta clase de intereses el más sensual- que de la pura acción resulta. Pero siempre tendremos que la fantasía subsiste y permanece, bien que se manifieste en otra forma. Declarada ilegal la imaginación, ¿cuál es la cualidad maestra del novelista? El sentido de lo real, contestan los apóstoles de la nueva estética.

El sentido de lo real, ese don que poseen tan pocos, algo que se rebela a la definición, pero que no por eso deja de ser una cosa real y positiva. Pero esa facultad, ese genio de observación, requiere que al llegar la hora de la labor artística, lo que han llamado expresión personal, corresponda en vigor, en relieve, en colorido, a la intensidad de la visión que, por decirlo así, se devuelve. Y, o mucho nos equivocamos, o en estos viajes de fuera adentro y de dentro afuera tiene algo que ver la imaginación.

Consignada esta débil protesta en favor de una palabra tradicional y querida - seamos conservadores en algo-, conste que estoy lejos de hacerla extensiva al fondo de la idea. Un escritor discretísimo ha dicho que el talento era la imaginación. ¿Nos será lícito afirmar, y no es otro el alcance de estas observaciones, que la imaginación es el talento?

A propósito de talento. El Sr. Pérez Galdós, que lo tiene tan grande, parece que lo dirige hoy por nuevos rumbos. Lo hemos dicho al principio: el naturalismo se impone decididamente, y he aquí al Sr. Galdós, el ilustre autor de tantas novelas históricas y novelas de tesis, todas ellas muy justamente celebradas, abandonando las realidades del pasado y renunciando a resolver problemas para estudiar la vida que le rodea y arrancarle su continuo y palpitante drama.

¿Hemos de felicitarnos por ello? Seguramente, y no tanto porque el procedimiento sea el que más se ajuste a las exigencias del día, no tanto porque el camino emprendido sea el solo que conduzca a creaciones sólidas y durables, como por las condiciones personalísimas que abonan al que tomó la iniciativa. Un movimiento en tal sentido, recibiendo del Sr. Galdós su primer impulso, habrá de ser forzosamente fecundo en resultados, sin los peligros de una iniciativa extremada y torpe. Claro está que se puede ser muy naturalista y escritor muy inhábil. Por otra parte, es ley que éstos, los torpes, procuran siempre suplir su falta de talento con audacias de ejecución, que venturosos 
ellos si producen ruido y escándalo: no hay naturalista de menor cuantía que no envidie en Francia al autor de Las hermanas Vatard, no ya por los primores de su obra sino por la frase que le dedicó la crítica recalcitrante: Huysman es el. artista de la inmundicia.

El naturalismo, en manos del Sr. Galdós, está ciertamente en buenas manos. Más tarde vendrá la extrema izquierda publicando horrores. Pero como toda anarquía acaba por una dictadura, el público acatará sólo al Sr. Galdós,

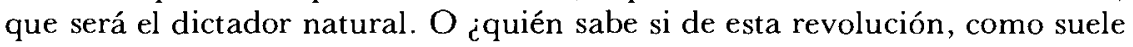
acontecer, surgirá algún otro genio desconocido que avasalle a la desenfrenada turba?

El Sr. Pérez Galdós empieza su tarea por donde debía empezar, por el pueblo. Y he aquí lo que ha inducido al error general de que el naturalismo tiende exclusivamente a agitar el fondo social y hacer subir a la superficie todo lo que en él hay de abominable y feo. Como hasta ahora, en efecto, la novela naturalista intimó [de modo] preferente con la vida popular, sin duda por su más rico contenido, y sobre todo, porque para la misión civilizadora que se impuso, para su misión de verdad, más se prestaba a su propósito el dirigirse desde luego al pueblo, que es quien más necesita de esa verdad, se concluyó universalmente que el naturalismo limitaba el horizonte de la novela, no viendo más allá de las clases bajas. Aquí entra, además, lo de calumniar al pueblo, lo de que el pueblo es mejor de lo que se le pinta, etc., etc. El pueblo será bueno o malo; de todo hay. Prescindamos de que las cárceles no suelen recoger su contingente entre la burguesía; de que esas pobres mujeres descotadas que pasan y vuelven a pasar ante los escaparates iluminados no proceden de la clase de duquesas; de que esos niños, próximos a micos del consabido patio, que os hurtan el reloj o el pañuelo, no son hijos de propietarios, sino del arroyo ...; prescindiendo de todo esto, sobre lo que, repetimos, no está de más decirle la verdad al pueblo, el naturalismo tiene por materia imponible todas las clases, todas las esferas, toda la vida. Zola ha recorrido ya la gama. El drama del pueblo en el Assommoir; en Una página de amor, el de la clase media; la vida del clérigo en Su Excelencia Eugenio de Rougon; la vida del teatro y de los grandes círculos en Nana...

El Sr. Galdós no aborda al pueblo con esa franqueza ruda característica de la nueva novela. Bien es cierto que La Desheredada no desarrolla su acción en esas latitudes peligrosas en que procede velar la frase sin menoscabo de la verdad, ni aun es novela popular en cierto amplio sentido, por más que se hayan pedido al pueblo sus principales datos y que del pueblo sean sus más animadas figuras. Toda la novela de Galdós, en cuanto al argumento, puede condensarse en esta forma. Isidora está convencida, merced a ciertos papeles que hubo a su orfandad, que tanto ella como su hermano Marianín no eran hijos de aquel Rufete, secretario de un gobierno de provincia cuando Dios quería, cesante casi siempre y muerto por fin en la jaula de un manicomio loco de remate. Los papeles rezaban que una hija de la marquesa Aransis había tenido, fruto de muy dramáticos amores, dos hijos que altas conveniencias pusieron en manos de los esposos Rufetes para que los criaran como suyos. Los niños eran Isidora y Mariano.

Cuadraban tan bien estas halagadoras noticias con la condición fantástica y vana de la joven, que desde aquel momento se diputó, con convicción profunda, por nieta de la marquesa de Aransis; iy aquí el fantasear de la niña 
sobre las grandezas de que en breve iba a tomar posesión como legítima señora!

Espoleada por su ambición viene a Madrid, con mil delirios en la cabeza y... un palmito muy agradable en verdad. Su hermano Marianín está en la corte con su tía la Sanguijuelera, haciendo mil diabluras que le valen el mote de Pecado por hacia el Barranco de Embajadores, absolutamente ajeno a su empingorotado origen.

Y aquí empieza el calvario de Isidora, el choque de sus sueños contra las terribles realidades. La vieja marquesa de Aransis califica su pretensión de absurda. Es preciso litigar; se entabla un pleito de filiación, pero también, jes preciso vivir! En suma: entre la demanda y la contestación, Isidora conoce a Joaquín Pez, que concluye por ser el padre de su hijo Riquín; después, hacia la dúplica, corre ya Isidora por cuenta del Sr. Sánchez Botín, activo diputado, que coge los chanchullos al vuelo; más tarde, cuando el alegato de bien probado, bajó ya algunos escalones...; es la querida de Juan Bou, litógrafo, catalán y socialista. ¡Ay! Cuando aparece la falsificación en uno de los documentos y la parte contraria pide el tanto de culpa, Isidora va a la cárcel, de la que sale siendo manceba de Gaitica, que acaba por hacerle un chirlo en la cara. ¡La pobre niña! Ya renunció al marquesado y sus pompas; ya no hay distinción en su compostura y hablar; ya no siente encogimientos aristocráticos. Desvanecidas sus acariciadas ilusiones, no es ella ya, no es Isidora, ¿qué importa todo, pues? Y haciendo un lío con las ropas que le quedaban, se dirige a la primera casa que encuentra en su camino. ¡Fin de la tragedia!

Por la complejidad de su carácter, Isidora, con ser la principal figura de la novela, no aparece con ese sello de realidad tan gráfica que marca a varios de los personajes que secundan la acción. La desheredada, toda fantasía, ofrece sus rasgos culminantes en medio de cierta vaguedad, como envuelta en la bruma de sus eternos sueños. Plebeya o de abolengo ilustre, opulenta o pobre, su vanidad loca habría de arrastrarle tarde o temprano a todas las caídas. Sus desarreglos, su pasión por el lujo, su desamor al trabajo junto a una ausencia casi absoluta de sentido moral la predestinaban fatalmente. Isidora tenía todas las condiciones de lo que llaman en Francia una entretenue. Y he aquí por qué se nota en ella algo indefinido y como exótico. Miquis se lo indica en cierta ocasión: Isidora no debió vivir en Madrid, no era este su medio natural. Esa mujer no es mujer española.

Consignemos de paso que en todos los devaneos y desordenado vivir de la Rufete, parece que apunta la ley de la herencia. El difunto Rufete, por lo poco que de él sabemos, había tenido también una imaginación tormentosa que le acarreó continuos desastres. Es como una muletilla de la Sanguijuelera el poco seso de aquel hombre, de aquel Rufete que los echó por puertas a todos con sus cavilaciones descabelladas...

Un poco afrancesado también es el bueno de Miquis, cuya insustancial cháchara, llena de gracia en ocasiones, recuerda ciertos tipos de bohemia parisién. Pudiera además censurársele por no haber emprendido la cura de su extraviada amiga a su debido tiempo, cuando charlaba tan por los codos merendando en los ventorrillos con ella. Un chico listo como él debía ver venir la catástrofe, y en vez de discursos extravagantes, hacer seriamente algo para contenerla. Acaso sería más explicable, ya que el hombre es así, que la apresurase por cuenta propia, pero no tiene perdón su pasividad gárrula ante una niña que no le era indiferente y cuya perdición se insinuaba con infalibles síntomas. 
Pero donde todo es verdad y sangre y vida, es en Marianín, en Juan Bou, en la Sanguijuelera.

Marianín, Pecado por mal nombre, es el jefe de los muchachos de su barrio, y eso que allí está el Majito, muy terne y muy gentil, y Zarapicos y Gonzalete, personas que han vendido ya en este mundo muchas manos de $\mathrm{La} \mathrm{Co}$ rrespondencia y de El Imparcial, y que no se dejan imponer fácilmente. Marianín, con sus 14 años, está ya un poco agriado de la vida; su tía le puso a trabajar en un taller horrible, donde hacen sogas de esparto y él da perpetuamente a la rueda.

En cuanto a civilización, poca cosa. La Sanguijuelera opina que el mejor colegio es trabajar y criar callos. ¡Bastante sabía de letra Rufete, y era un hombre inútil para todo! Marianín trabaja, pues, pero cuando se separa de la rueda infernal vuela en busca de sus compañeros y reivindica su calidad de niño. ¿Qué hermoso capítulo aquel de "Hombres"! Marianín mata a Zarapicos de una puñalada, De aquellas cosas que pasan... según la muletilla del niño.

Después de muchos meses de cárcel, Marianín vuelve a la vida vagabunda. Intenta otro oficio, desaparece, nadie sabe de él, y, por fin, se le encuentra de nuevo. Ha estado en el hospital; vivió en un tejar de las afueras; se nota en él cierta somnolencia estúpida.

Y vagamente Marianín odia muchas cosas. Odia a los que pasean en carruaje, a los que viven en palacios, a los poderosos... Uno de ellos, de quien sabe que es un grandísimo canalla, le llama granuja un día y le cruza la cara con un látigo. Mariano toma notas.

Una tarde se pone camisa limpia, se acicala y se dirige al centro de Madrid. ¡Se hablará de él aquel día! Una gran muchedumbre se extiende por la calle Mayor. Suenan músicas, se aproximan caballos al trote. Es la comitiva real que vuelve de Atocha. De pronto Marianín saca una pistola y dispara. ¡De aquellas cosas que pasan! Todo esto es de mano maestra.

¿Qué decir de Juan Bou, litógrafo, catalán y socialista? Sus declamaciones contra el orden de cosas, su odio a las sanguijuelas del pueblo, sus noticias de Barcelona respecto al movimiento social, todo cede en un punto cuando saca su segundo premio de la lotería y puede comprar los favores de Isidora. También él paró en ser sanguijuela del pueblo. Y hay tanta verdad en el catalán patriota, que se le ocurre la idea de ir a encargarle unas tarjetas.

La Sanguijuelera es un tipo pintado con amor. Cariñosa y brutal, sarcástica ante todo lo que no sea un hecho tangible, el marquesado de su sobrina la pone fuera de sí, maltratándola cruelmente de palabra y de obra. ¡Pero cómo quiere a Marianín, y cómo se vienen las lágrimas a los ojos cuando la vemos arrojar al coche del monarca aquel memorial, y decir: “iRey mío, niño-dios, perdón!»

La dilatada dinastía de los Peces, Peces grandes y pececillos que colean en la gran pecera del presupuesto, da lugar a uno o dos capítulos deliciosos que acreditan al Sr. Galdós como maestro en el donaire. No creo preciso consignar, tratándose de España, que todos estos Peces son de una realidad conmovedora.

Tiempo es ya de terminar este artículo. El señor Galdós, en resumen, ha hecho una magnífica novela y determinado una evolución que, por él y por los que le sigan, ha de ser de gran trascendencia en nuestra literatura.

La corriente se impone. Sería estúpido luchar contra ella. El novelista, 
en adelante, se verá precisado a trabajar en firme y a ahondar, ahondar siempre. Si queréis que viva, llevad la vida a vuestra obra.

Un crítico ilustre creía observar en los libros de un estilista célebre algo que era como un gran silencio. ¡Por allí no pasaba el hombre!

En libros como La Desheredada parece que se percibe el rumor de la multitud.

\section{TEXTO 4}

Luis Alfonso, "Crónica del lunes: La desheredada, de B. Pérez Galdós - El capitán Veneno, de P. A. de Alarcón", La Época, Hoja literaria de los lunes (Lunes, 7 de noviembre de 1881).

En La familia de León Roch - cuyo apellido, por cierto, está mal ortografiado, pues siendo valenciano debiera escribirse Roig, sin lo cual se lee Roe-, en la citada penúltima novela de Pérez Galdós empezó a escarabajearme una idea, que ahora, al leer La desheredada, hase fijado en mi cerebro con más pertinacia que la gota de mercurio que por el suyo siente correr el mísero orate Tomás Rufete, padre de la protagonista de la obra.

Esta idea, lo diré pronto y claro, es que el insigne novelista se aprovecha de Zola.

"Se aprovecha" he dicho, porque, a mi entender, esta es la frase que mejor traduce mi pensamiento.

Pérez Galdós, como todas las inteligencias superiores, es personal y suyo en sus escritos; pero como todas esas inteligencias igualmente, il prend. son bien où il le trouve, como hacía Molière.

Significa, pues, lo dicho que P[érez] Galdós ha leído y estudiado a Zola - el cual, sea dicho de paso, yo, que he sido y soy idealista, tengo en mucho, en tanto como al mejor-, y de esas lecturas y esos estudios ha resultado que el novelista español ha tomado cuanto hay de bueno, o, si se quiere, cuanto hay de aplicable, de oportuno y de productivo en el novelista francés.

De ninguna manera ha llegado por ello Pérez Galdós a las hediondeces de L'Assommoir ni a las obscenidades de Nana; de ninguna manera tampoco ha perdido de su originalidad, de su carácter ni de su estilo; pero ha enriquecido con tonos su paleta, de igual suerte que Velázquez, sin dejar nunca de ser Velázquez, «se aprovechó» de Rubens; como más tarde Regnault, sin perder su personalidad, "se ha aprovechado" de Velázquez.

Si sobre esto insisto, antes que tratar de otra ninguna cualidad de $L a$ desheredada, es porque esta novela es, no ya por pinceladas que la vigorizan aquí y allá, como en La familia de León Roch, sino por su contextura, de la propia raza que las novelas de Zola.

Intriga dramática muy simple, fábula muy ligera, peripecias y sorpresas escasísimas o, en frase más breve y usual, poco argumento y prolija abundancia de pormenores filigranados con admirable minuciosidad y arte exquisito: he aquí el procedimiento literario actual de P[érez] Galdós y el de Zola y el de Daudet, su Rey colega en el trono de la novela francesa contemporánea. $\mathrm{Y}$ he aquí también el procedimiento pictórico de Meissonier, de quien, como 
notó con singular perspicacia un ingenioso crítico parisiense, deriva hoy la literatura en boga*.

La desheredada llena más de 500 páginas de un tomo en $4^{\circ}$ mayor. La misma novela, sin perder una sola pieza de su esqueleto - ni un solo músculo de su carne-, cabe en un tercio de lugar. Cierto es igualmente que la misma novela, sin fatigar al lector, ni desnaturalizarse, podía estirarse hasta otras 250 hojas.

En esto estriba, a mi ver, el defecto mayor de la obra. A más de la mitad de ella aún se interrumpe la acción para sacar a escena nuevos personajes y describirlos a ellos y a lo que les rodea. El predominio del detalle sobre el conjunto, de la parte sobre el todo, se sostiene hasta el final. Por eso, lo repito, la novela es larga. El camino que recorre es breve, pero a cada vuelta de la rueda, el autor describe detenidamente el surco que la rueda abre y el modo como gira y el trozo de vía por donde avanza.

Pero entiéndase bien, que no acuso de pesadez ni difusión sobrada el nuevo libro de P[érez] Galdós. Señalo solamente su umanera" como dicen los pintores; en la cual ha llegado, lo confieso sin rebozo, a la perfección admirable del nombrado Meissonier.

Con todo ello, ¿no hubiera resultado la obra más interesante, más fuerte, más tupida, si vale el vocablo, reduciendo a lo necesario sus proporciones?

Hay que tomarla ya como la hemos recibido y juzgarla como la hemos tomado. Fijémonos, pues, en ella, y consideremos ante todo su tema o argumento.

Pérez Galdós ha estado en él felicísimo. Sencillo es sobremanera, pero de gran monta. Una muchacha, nacida en cuna modesta y vulgar, pero dotada, por su mal, de ambiciosos pensamientos, enferma desde la pubertad de lo que llaman los alienistas "la manía de las grandezas». Cree, por su desgracia, que es hija natural de noble y acaudalada familia, que posee derechos indisputables que hacer valer y que Isidora Rufete será un día la opulenta marquesa de Aransis.

Su esperanza es un sueño: su fe un engaño. No tardan en descubrirlo las pesquisas judiciales. El padre real y efectivo de la alucinada Isidora intentó una falisificación, cuya burda trama no puede resistir a los ágiles y acerados dedos de la ley. Pero el desengaño llega tarde; Isidora, aferrada a su idea como el náufrago a la tabla, no se aviene, no puede ni sabe avenirse, a la vida humilde y laboriosa de la burguesa pobre. Puesta en alto la mira, y sin ojos más que para ella, da sendos tropiezos en la vida, de los que piensa redimirse al llegar a lo alto, como el pájaro seca en el espacio a la lumbre del sol el fango que manchó en tierra sus alas... Pero Isidora no las tiene, y hunde en él, no tan sólo los pies, como al principio, sino el cuerpo y hasta la frente, por último. Allí, en el lodo infecto del arroyo, donde se agitan tantas desdichadas... se pierde y hunde para siempre Isidora.

Esto es la novela, y nada más; esta es la figura desnuda; los episodios, los pormenores son el ropaje. La lección moral está maravillosamente ataviada con las galas de la pluma.

\footnotetext{
* "La littérature nouvelle procéde de la peinture de Mr. Meissonier. Chez le peintre et chez le littérateur, un même dedain de ce qu'on applèe l'intrigue dans un roman, et le sujet dans un tableau", A. Wolf, Le Figaro, febrero de 1880 ( N. del A.).
} 
Nunca con más esplendor ha desplegado el novelista esas galas... si cuadra este nombre a la autopsia sabia y exactísima de almas y cuerpos, de cosas y personas.

No ha vacilado Pérez Galdós aquí, como Zola, en convertir la pluma en gancho de trapero (valga la comparación por lo exacta) y remover la basura de la calle - esa basura donde el gallo de la fábula encontró una perla-, y si no ha llegado, como el autor de Nana, a designar las cosas por su nombre, así sea éste de la mayor crudeza, en lo cual, a la postre, no hace Zola sino imitar a los clásicos griegos y latinos, franceses y españoles -Aristófanes, Marcial, Rabelais y Cervantes, v.gr. - si a tanto no llega Pérez Galdós, porque en España existe todavía mucho rubor para los vocablos - lo cual no censuro, ciertamente; consigno- ha sabido por hábiles onomatopeyas reproducir sin ofensa, a la vez que sin ambages, el lenguaje rufianesco hoy en uso, no sólo en mancebías y garitos, sino en cafés, Casinos y salones.

$\mathrm{Y}$, en resolución, el autor de La desheredada no necesitaba revalidarse de novelista; mas si lo hubiera necesitado, bastaba el libro en cuestión para ganarle el título.

El diseño de los tipos, la pintura de los lugares, la descripción de los sucesos, la expresión de los sentimientos y pasiones es magistral: conservando el sabor castizo, en ocasiones, de Hurtado de Mendoza o de Mateo Alemán, grandes pintores de pícaros y vida picaresca, alcanza en otras el análisis hondo y escrutador de Balzac; llega a la reproducción gráfica, y sencilla en la forma, de los movimientos del carácter, a la manera de Dickens, y penetra, por último, en el espíritu, por decirlo así, de las cosas, anima a lo inanimado, según hacía con pluma de oro Gautier, y Daudet y Zola con pluma de hierro.

En resolución, Isidora Rufete queda desheredada; pero La desheredada ha venido a aumentar la rica herencia que legará Benito Pérez Galdós a las letras españolas.

No es menester, para tratar del último libro de P[edro] A[ntonio] de Alarcón, meterse en dibujos ni apelar a filosofías, como para tratar del último de P[érez] Galdós es menester. Claro como el agua y simple como un niño es El capitán $V e n e n o$, digno camarada, a mi entender, aunque en distinto género, de $E l$ sombrero de tres picos.

Se ha dicho de esta historieta que es un cuadrito de Goya; pudiera decirse de aquel "estudio del natural" que es una acuarela inglesa; de Herkomer, v.gr. Pintura suave y reposada, honesta y apacible de interior; solamente que en esta placidez británica penetra bruscamente - por la ventana del cuarto bajo de la calle de Preciados, donde Angustias y su madre socorren al capitán Veneno- un rayo ardiente y vivo del sol de España.

El asunto de la novela es antiguo; data de los tiempos mitológicos: Hércules, hilando a los pies de Onfala, fue el primer capitán Veneno que cayó de hinojos ante la primera Angustias. Además, todos los poetas y escritores han venido, siglo tras siglo, confesando lo propio; desde Maximeno, que decía:

Cras amet qui nunquam amavit;

Quique amavit, cras amet, 
hasta Voltaire, que escribió en el pedestal de una estatua del amor:

Quique tu sois, voici ton maitre:

Il l'est, le fut, ou le doit être.

El capitán Veneno no amó ni pensaba amar, y zahareño, y feroz, como ninguno, conviértese en sumisa oveja, por arte y gracia de la gallarda moza... y del ingenio no menos gallardo, de Pedro Antonio de Alarcón.

Más inventiva, más vigor dramático habrá puesto en juego -y era más oportuno- en El escándalo o El niño de la Bola; más donaire (clásico) como el rumbo de la maja habrá puesto de relieve en El sombrero de tres picos, pero más primor de ejecución, nunca.

Leer el diálogo in articulo mortis que media entre el capitán y la condesa de Santurce, sin sentir el llanto acudir a los ojos; leer el coloquio in extremis, de soltería... que se entabla entre el mismo capitán y Angustias, sin sentir retozar en los labios la risa, por difícil, si no imposible, lo tengo.

$\mathrm{Y}$ al artista de la palabra que así remueve los sentimientos y se apodera de las voluntades, ¿qué agria censura ni qué dura crítica lo derriban de su pedestal, del que obtiene el talento, y que es más duradero, y más firme, y más glorioso que el mismo sillón académico... porque se sostiene el escritor en él aún en la otra vida?

Tomad, ¡oh, lectores!, El capitán Veneno; recorred despacio sus páginas una a una -ni más ni menos que como se saborea un exquisito manjar o se paladea un vino exquisito- y cuando lleguéis, de un solo aliento, a la última página y cerréis el libro, condolidos y como enojados de que haya terminado tan pronto, decidme en conciencia: ¿Debo o no debo proponer para capitán general al capitán Veneno? 